\title{
Selling the Unemployed: the Performance of Bureaucracies, Firms and Non-profits in the New Australian "Market" for Unemployment Assistance
}

Mark Considine

Accepted in Social Policy and Administration (Wiley, 2000)

\begin{abstract}
Major changes to the organization of welfare programmes indicate the emergence of a new welfare state (NWS) model which claims to put an end to the traditional "one size fits all" ideal of universality and standardization. The stated aim of such arrangements is to improve service for the client, reduce costs for the taxpayer and lift the performance of the system as a whole. The Labor government reform of the Australian employment assistance system between 1994 and 1996, and the Coalition's first modifications of this scheme in 1997, provide a means to investigate the performance of a NWS system which uses private and public agencies to provide a basic, mandatory employment assistance service. Using verified data on the comparative performance of public, private and non-profit agencies and qualitative data from a study of Best Practice among high-performing agencies, the study shows that this system produces greater service variation than the previous universal service system. Overall, the system also does better in achieving employment and education outcomes with long-term unemployed clients. However, the study shows that such outcomes differ between different classes of client and between different types of service provider. In particular, outcomes are lower for the more disadvantaged, and are higher for those who have training programmes available to support them.
\end{abstract}

Keywords: Welfare reform; Employment assistance; Quasi-markets; Australia 


\section{Introduction}

A new welfare state (NWS) model is emerging in countries such as the USA, Australia and New Zealand, and is now being entertained in Europe. Al- though far from homogeneous and containing numerous contradictions, the model is distinguished by its attempt to give expression to President Clinton's oft-quoted commitment to "end welfare as we know it" ( Jennings and Krane 1998: 171). The new model seeks, inter alia, to bring markets and entrepreneurial elements into play within the conduct of social welfare programmes. Le Grand and Bartlett (1993: 3) have described these changes as a "major offensive against the bureaucratic structures of welfare provision”. Osborne and Gaebler (1993: 79) claim that "when service providers must compete, they keep their costs down, respond quickly to changing demands, and strive mightily to satisfy their customers". The use of economic incentives is com- mon in NWS initiatives and may be directed both at clients of programmes and at programme providers. This strategy opens up for consideration the extent to which "public goods" may be achieved through an appeal to private interests.

In considering this problem Hardin (1978) identified the "tragedy of the commons" as a consequence of inadequate government restraint on private interest. However, more recent research such as that by Ostrom (1990: 182) has defined a path between state and private control of key resources, concluding that "the success stories were mixtures of public and private instrumentalities". In all these cases researchers note a renewed interest on the part of policy makers in finding appropriate alternatives to both public monopoly and private exploitation.

This interest has recently found wide support in the social policy field and has manifested itself in the widespread experimentation with market-like techniques for allocating resources, selecting providers of service, and matching clients to programmes (Bartlett and Harrison 1993; Glennerster 1991; OECD 1993). Not only are relationships between actors in these countries not removed from market determination, or decommodified according to EspingAndersen's (1990) celebrated typology, they are actually re-commodified, but according to a new set of publicly determined principles.

In organizational terms this new welfare state resembles a quasi-market rather than a unified system of public benefits. Governments issue contracts, set standards, regulate service 
agencies and run their own quasi-businesses. Contracts become the primary means for coordinating behaviours, money is the chief instrument for achieving stated purposes, and stronger regulatory enforcement becomes the method for creating compliance by participants of all types (Osborne and Gaebler 1993; Barzeley 1992; Kooiman 1993; Considine 1999).

Despite considerable enthusiasm on the part of governments pursuing these reforms, and notwithstanding the existence of a growing literature on the theoretical virtues of such systems, a number of questions remain unanswered. In particular we need to know much more about the way different types of contractor perform under these conditions. Are the claims made for private competition realized? If there are differences between different types of service provider, is this due to different strategies for dealing with clients? Does this simply mean that private agencies seek to treat the easier cases and leave the difficult problems out of their repertoire? If local strategies vary as much as might be hypothesized, is the sum effect good or bad for the most disadvantaged clients, or merely a resort to statesponsored "creaming"?

In this study we examine the development of the market for unemployment assistance in Australia, where one of the most radical and comprehensive manifestations of the new welfare state model was implemented between 1994 and 1998. Employment assistance and the public welfare payments which accompany it are central elements of most welfare state models of assistance. In the 1990s this field was split by a contentious debate over which programmes deliver the best results for government and for clients. Following innovations in the USA during the 1970s and 1980s, many OECD systems now involve attempts both to provide income support for the unemployed and to require various forms of job search, training and community work as the price for assistance.

The implementation of the US Family Support Act of 1988, including the Job Opportunities and Basic Skills Training (JOBS) Program, sponsored a variety of state-level experiments in the delivery of employment programmes. These, and their forerunners under the Work Incentive (WIN) Program, have generated a substantial evaluation literature which underpins reforms in a variety of countries. The conclusions reached by evaluators have been equivocal and a large degree of uncertainty remains in regard to the explanation of good results where good results have been obtained (Friedlander and Burtless 1995; Brasher 1994; Handler 1995). These debates concern two different sets of issues. The first relates to the incentive 
structure provided for welfare recipients and whether this encourages a return to work. In this vein programmes have attempted to manipulate the mix of different benefit levels, extra health and childcare assistance and other pay-offs for taking a job rather than staying on welfare (Nathan 1993). A second set of changes has sought to alter the organizational environment in which clients are given benefits and introduced to job vacancies, training opportunities and assistance with personal barriers to employment such as addiction, disability and mental health problems (Pavetti et al. 1996).

While no discussion of the role of these programmes can ignore the first set of issues, an assessment of the impact of change upon the nature of governance, and particularly upon the structure of the welfare state as an institution, will logically focus upon the second set of changes. Here we find a range of findings from the US studies of experimental programmes and from other systems which give shape to a new model (Nathan 1993; Friedlander and Burtless 1995). Put simply, these studies point to a new interest in ways to devolve public service functions to more flexible forms of local service delivery. Chadwin et al. (1981: 373) follow this line when they conclude that "structural, managerial, and operational practices are associated with high performance". Proponents also promote a variety of operational methods to restrict the "permissive character" of programmes for the poor (Mead 1986: 1) by making officials more accountable for creating a local system of "mutual obligation", collecting child support payments from the non-custodial parents of job seekers needing childcare, and by encouraging officials to require clients to accept "even a dead-end, low-wage position" (Nathan 1993: 45).

With the exception of those states which contract out the training and specialist services for addiction and career guidance, most of the experimental programmes upon which the Welfare-to-work model has been based are public services (King 1995). By the 1980s the growing interest in programme reform began to be matched by a broader public management agenda which favoured the use of private agencies. Organizational economics through its various critiques of opportunism, capture and goal displacement sought to convince government that its reliance upon a unified system of public service programming was out of date (Foster and Plowden 1996). The bureaucratic approach was viewed by critics as incapable of delivering a release from the cycle of welfare poverty, benefit-driven budget increases and long-term unemployment. The alternative means to administer programmes was seen to be privatization, deregulation, contracting-out and competition among service 
providers (Osborne and Gaebler 1993; Le Grand and Bartlett 1993). Among the most enthusiastic supporters of this approach were Australia and New Zealand where Labour governments of the 1980s sought to "transform their societies and political economy" using these instruments (Castles et al. 1996).

\section{Background to the Australian Employment Assistance Programme}

The intersection of the main elements of US Welfare-to-work programmes and this new interest in privatized alternatives to public bureaucracy constitute the core features of what we are calling the New Welfare State (NWS). In operational terms the model includes the use of multiple service providers drawn from the public, non-profit and for-profit sectors. These agencies tender for contracts and are subject to various regimes of contestability and competition. They are encouraged to be selective in the forms of service they deliver to clients and they are paid according to a mix of "file opening fees" and payments for specified outcomes. They are free to decide their own method of organization and to contract staff as they see fit. Clients must accept service from the agency they choose, or to which they are referred, or risk losing their income support.

Australia's comprehensive reforms to its employment assistance system were enacted between 1994 and 1997 and provide a unique opportunity to examine the impact of the NWS model. This system of competitive provision of assistance was first defined in the Labor government White Paper, called Working Nation, as an effort to give assistance a stronger client focus. This was also defined as an alternative to "processing large numbers of job seekers through relatively rigid national programmes" and instead to address client needs on a more individual basis (Working Nation 1994: 127).

As a means to deliver this promise the government elected to bring a large number of private welfare and for-profit agencies into the core service field: "Healthy competition will lead to service improvement" (Working Nation 1994: 127). This new approach was characterized as flexible, innovative and competitive and proponents frequently contrasted these claims with the alleged weaknesses of the old welfare state with its universal provision of a highly standardized and centrally controlled group of services. This older model was said to result in an inflexible "one-size-fits-all" approach to service delivery. The first reforms occurred between 1994 and 1996 and involved: 
- individual case management for all long-term unemployed clients;

- referral to both jobs and subsidized work and training;

- continued use of a large public-sector service provider (Employment Assistance Australia, EAA);

- contracting of more than 300 new private providers (Contracted Case Management agencies, CCMs);

- regulation of this quasi-market by an independent government regulator (ESRA);

- payment of private providers on a fee-for-success basis;

- competition between providers on quality but not price;

- empowerment of unemployed clients to choose their preferred agency and negotiate a service contract.

Between 1994 and 1996, under the Labor government, one-third of the public assistance programme was moved out of the core public service and given to contractors in both forprofit and non-profit agencies, subject to regulatory oversight by the Employment Services Regulatory Authority (ESRA). In addition to case management, the agencies had access to a variety of training programmes licensed and funded under the Jobs Compact which aimed to provide all long-term clients with either training or a job (Finn 1997). Phase 2 of these reforms began in March 1996 when the newly elected Conservative government abolished the Jobs Compact training programmes and also indicated a desire to make labour market assistance both more limited and more clearly linked to the client's "capacity to benefit". The revised scheme included:

- increase of private contractor role from 30 per cent to almost 50 per cent of the "market";

- closing of brokered training programmes;

- delegation ("cashing out") of remaining training funds to contractors;

- payments to contractors now driven only by exits to jobs;

- public agency run on same terms as contractors. 


\section{Research Questions and Methods}

Evaluation of the employment impacts of programmes is known to require several years, and most evaluations of such programmes rightly stress the need to adopt experimental methodologies which screen out non-programme effects. This paper does not attempt such an evaluation but instead asks what difference it makes to involve private contractors in the "core activities" of the public service. Important indicators of the impact of these new models of welfare provision can be gained by considering similarities and differences in their capacity to treat job seekers. These indicators also provide a baseline for considering longerterm impacts of such "mixed economy" models being developed elsewhere, including in the New Deal programmes of the Blair government. For these purposes performance is defined as placement of long- term unemployed people into jobs which last at least 13 weeks, or successful referral into training and education which lasts at least 13 weeks.

These performance criteria are also the ones used by government to decide the payments to be made to private providers so they are both obvious and transparent, even if they do not tell us everything we might wish to know. Other non-economic aspects of these reforms are considered elsewhere (Considine 1999). These performance data are also examined from the viewpoint of certain important socio-economic differences between clients. Very long-term cases, those who are disabled or who are from highly disadvantaged indigenous populations are compared with those less disadvantaged to see whether the entrepreneurial model of welfare impacts evenly. The two most basic research questions to be asked of this reform are: What difference does the system of selective interventions through quasi-markets make to performance? And, if some types of agency do better, what factors best help us to explain their superior performance?

Two different research methods were employed to answer these questions. Answers to the first question are based upon census data collected by the public regulator, ESRA, for the period up to October 1997. These are derived from official government statistics on the numbers of clients entering case management and exiting to both training programmes, supported employment and regular jobs. We are able to compare these basic performance scores for all private operators (called contracted case managers, or CCMs) and the government organization (called Employment Assistance Australia, or EAA) which continued to provide public services to the same types of client. 
Some key indicators of the relative effects of these reforms upon different types of clients are presented. These employ two different methods for classifying the severity of disadvantage experienced by long-term unemployed clients, all of whom are job seekers drawing benefits for twelve months or more. The first method is a four-level model of disadvantage which was used up to the end of 1996 when that system was condensed into a two-level model. These are called the client classification levels (CCL) A and B.

The first important finding of this study is that the performance scores for public and private providers show a greater variation among private providers than for sites within the public network, with the latter more likely to be at the extreme ends of the performance curve (see figure 1). Since the public provider is an organization which was previously the only provider we might reasonably take this as a measure of certain "before and after" characteristics. This not only indicates that "mixed market-type" systems produce greater service variety, it also suggests that the public provider is more likely to be an average-to-good performer than a poor or excellent one. Since the public provider is also a larger organization than any of its competitors, we may also conclude that scale of operations accounts for its more even performance.

In order to explain why some private for-profit and non-profit organizations perform better than others we then selected a group of top performers and compared them to more average agencies in a study of Best Practice in this new industry. Here the focus was upon performance at individual sites rather than across whole organizations because other studies have pointed to local offices as the primary locus for differences in staff and client behaviour (Handler and Hasenfeld 1997; Hamilton and Brock 1994; US General Accounting Office 1995; Martinson and Friedlander 1994). 


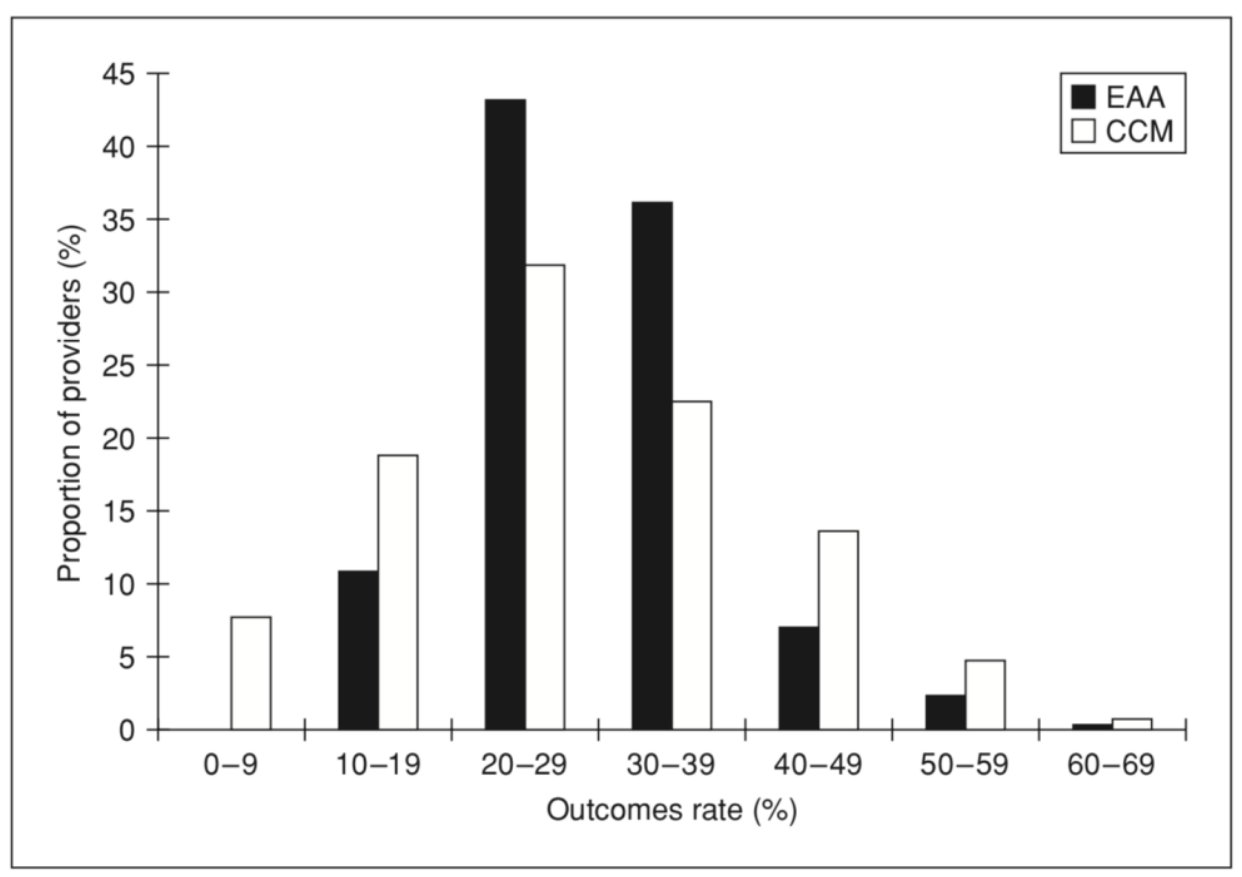

In reviewing the strategies of best and average sites the study compared success rates for all sites defined as placements into full- or part-time work or full-time education as a percentage of all job seekers available for placement at this site. All private contractors were ranked into five categories with 0 representing the bottom 10 per cent of performers, 1 the next 15 per cent, 2 the middle 50 per cent, 3 the next 15 per cent and 4 the top 10 per cent of performers, based upon the shape of the frequency curve for the system as a whole. A multiple regression analysis was performed to identify independent variables which would provide a statistically significant explanation of contributions to performance at each level for each site. ${ }^{1}$ The variable list included period in business, severity of the local labour market (using official unemployment rates ${ }^{2}$ ) and several client background variables such as percentage of youth, disabled and women. The sites proved to be remarkably similar in regard to these background variables, giving confidence that conclusions about their performance were not due to selection bias. Performance was not related to whether or not the agency at that site had harder or easier clients than others in the sample. The item which accounted for virtually all variation between sites was "period in business", with more newly arrived providers doing worse than those in business for ten months or more. Consequently adjusted scores were not calculated for any of the recently arrived sites. These agencies were not included in the qualitative study. 
The selection of sites was then based upon stratified random selection designed, other things being equal, to ensure a comparison of specialist and generalist providers, private for-profit and non-profit, rural and metropolitan agencies, and whether or not the site was a stand-alone case management organization, or was part of a "mixed business" of employment and other activities. This sampling strategy provided the first important finding of the study. No highperforming site could be located which was other than a "mixed business" type. All of the top-performing sites also ran training services for the unemployed or for employers, ran Job Clubs or were service providers in the apprenticeship and trainee sectors. The importance of this finding is discussed below.

Each of the twenty sites across the country was visited by two members of the research team in mid-1997. Case managers and site managers were interviewed using a structured interview schedule which also served as a framework for later entering responses on to a standard coding instrument. At each site a focus group discussion with approximately eight job seekers was conducted. These were tape recorded and the tapes and summaries were provided for other members of the research team. In each intervention the respondents were asked to describe their current experience with the programme. Questions included enquiries concerning the method of client selection, assessment, referral to jobs, sanctioning, use of training programmes and contact strategies for employers and other agencies. Researchers then participated in three debriefing sessions at which they were required to classify independently the strategies they had observed by defining the roles played by different aspects of the local system. Comparisons were then made of different styles of intervention, common methods for dealing with problems, and the effects of key aspects of the programme such as client choice, case manager discretion, leadership by the site manager and relationships with employers. These findings provided the basis for the results presented below.

\section{Results 1: the Performance of the Quasi-market}

Three attributes define quasi-markets and distinguish them from activities usually defined as either market or hierarchy (Williamson 1975: 7-9). First, unlike traditional welfare systems which rely on a single organization or public bureaucracy, in a quasi-market there are multiple independent agencies and each has a share of a common system of public service 
provision. Second, unlike traditional markets, these organizations will be a mix of for- profit and non-profit organizations, including providers owned and operated by government itself. Third, consumers do not purchase services with money but either use "vouchers" or have services purchased on their behalf by a central government purchaser (Le Grand and Bartlett 1993: 10).

In 1994 the immediate consequence of the implementation of this form of contracting was that the share of services provided directly by government fell by 20 per cent, and by October 1997 the public and private sectors had almost half the clients each. In other words, the basic task of assisting unemployed people to find work was subject to significant levels of privatization.

Figure 2: Exits from case management (3-month moving average)*

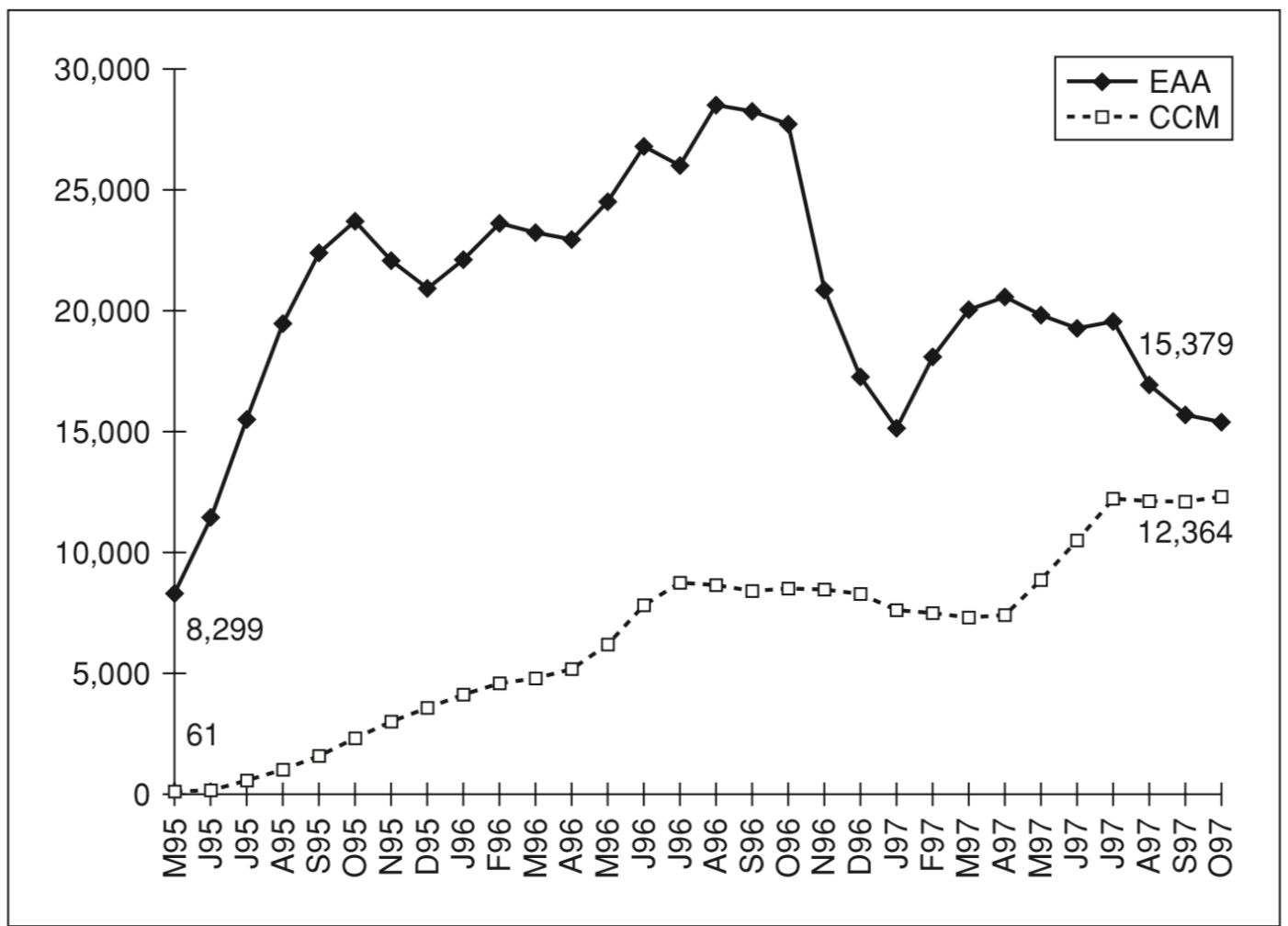

* The three-month period represents the minimum period (13 weeks) for which agents must sustain successful outcomes before receiving their full fee. A smaller fee is provided at case opening stage.

The total number of clients receiving such services also fell by approximately 25 per cent, largely as a result of new government budget cuts and changed priorities. Unemployment in Australia remained high throughout the period, fluctuating around the 9 per cent level. 
The performance of the two different agency types (EAA is the government-owned provider and the CCMs are the private agencies ${ }^{3}$ ) described in figure 1 above, shows that the government service continued to have the greater proportion of average and mediumperforming sites and this was reflected in the measure of exits from the programme described in figure 2. The government service maintained its stronger performance throughout, suffering most in late 1996 when the availability of training programmes declined as a result of new government policy after April 1996. Figure 3 shows that the system's overall performance changed significantly when these subsidized programmes were cut back. A subsidized outcome was one achieved by placing a client into something other than an open job vacancy. This performance slump did not move towards recovery until one year later.

Figure 3: Outcomes, subsidized and unsubsidized (3-month moving average)

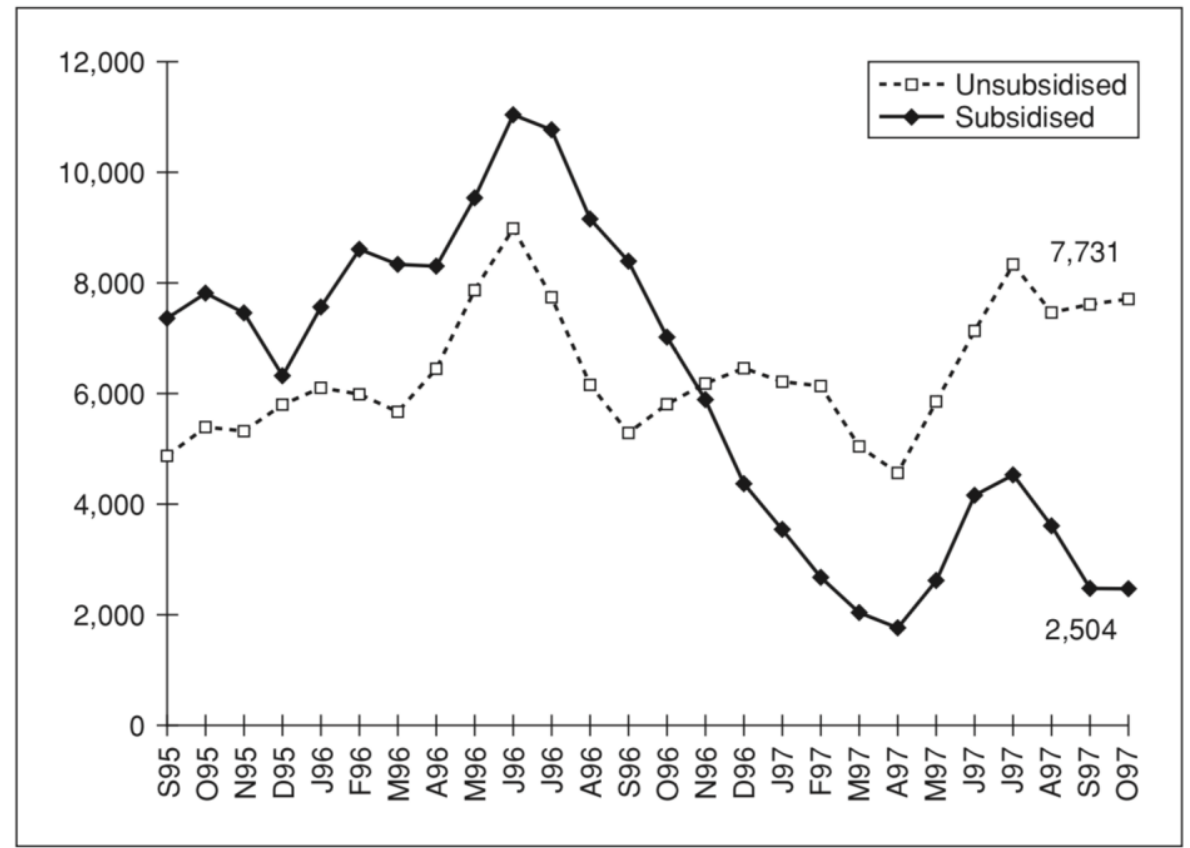

Importantly, the performance of the system as a whole varied according to the severity of the barriers to employment faced by clients. In other words this multi-provider, or "mixed economy" system appears to have produced higher levels of selectivity and discretion. The system of outcome-based payments for success favoured agencies that concentrated on those job seekers closest to being ready for work. In other words there was a significant element of "creaming". To qualify for assistance clients had to have been out of work for at least 12 months and because of queuing problems caused by the backlog of clients eligible for 
services, most were in fact unemployed for 18 months or more. As described above, the client group was divided by government into two main severity groups. Category A (CCL A) clients were defined as those with less severe barriers. They were more likely to be younger, better skilled and less impaired by health or intellectual disability. Category B (CCL B) included very long-term unemployed clients and those with significant skill, health, locational and personal barriers. Less disadvantaged clients did significantly better than others, although it is also interesting that both types suffered equally when subsidized programmes were withdrawn by government (figure 4).

Figure 4: Outcomes, less and more disadvantaged clients

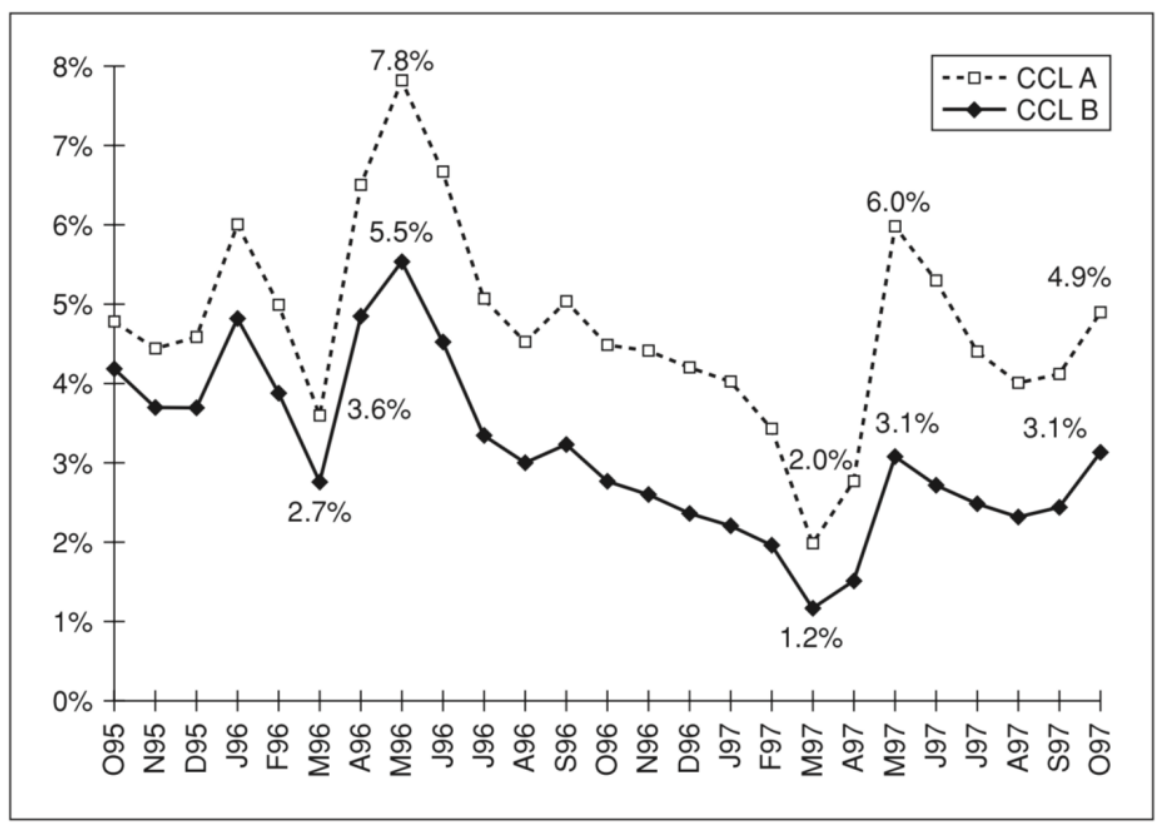

These figures combine both public and private clients. However, other data show that more disadvantaged clients were found in the case lists of non-government agencies up to the middle of $1997 .{ }^{4}$ This appears to have two likely explanations. First, the private sector received a high proportion of initial referrals of disadvantaged clients as a result of government policy to fill the first round of contract placements from the back of the benefit queue. This resulted in clients with up to five years' unemployment being a disproportionate share of the first year's cohort going to the new agencies. Since agencies were paid more for the more disadvantaged clients, this provided both funds and further incentives for good performance among this group. These clients were allocated to individual sites by a mix of 
choice and referral, choice being the option only where more than one local provider was available and where the client expressed a preference.

Interview and focus group data indicated that many disadvantaged clients chose private providers because they had already had long relationships with the public office and sought a different experience. Some also indicated that they had had sanctioning problems with the government provider and wished to distance themselves from government in the hope of a less troubled existence. Significantly lower sanctioning rates by non-government providers suggests that this choice may have been rational (DEETYA 1996: 32; Considine 1999). Second, many of the clients with severe disadvantages were classified as requiring specialist support for drug dependence, mature aged support and Aboriginal and Torres Strait Island (ATSI) special needs. These specialist services were more likely to be provided by nongovernment agencies with an established role in serving these sub-populations (see figure 5). After the government moved to create a more distinct separation of the public pro- vider role from the organization allocating clients to agencies (the Com- monwealth Employment Service), and after the classification system was compressed from four to two severity types, the distribution of types across agencies became significantly less unequal. In other words the establishment of specialist services delivered by expert non-profit organizations which also ran training programmes appeared to stimulate a flow of such clients away from the public agency.

The experience of very disadvantaged clients varied according to whether or not there were special training and assistance programmes (leading to subsidized outcomes) available to their case managers. Although in theory these programmes favoured those with the greatest barriers to work, in practice the abundance of opportunities created by the Keating Labor government meant that this system was supply-driven. Case managers would be notified of new programmes in their area which needed to be filled. These programme providers were required to maximize the flow of their trainees moving from unemployment to subsequent open employment and therefore had strong incentives to select the most marketable intake. However, a large number of such programmes had a target audience of workers with defined barriers. Consequently, the performance of specialist case management agencies became more than usually dependent upon the existence of subsidized programmes. When these were withdrawn the performance of these specialist agencies declined dramatically. For example, figure 5 shows that these impacts were particularly severe for Aboriginal (ATSI) job seekers. 


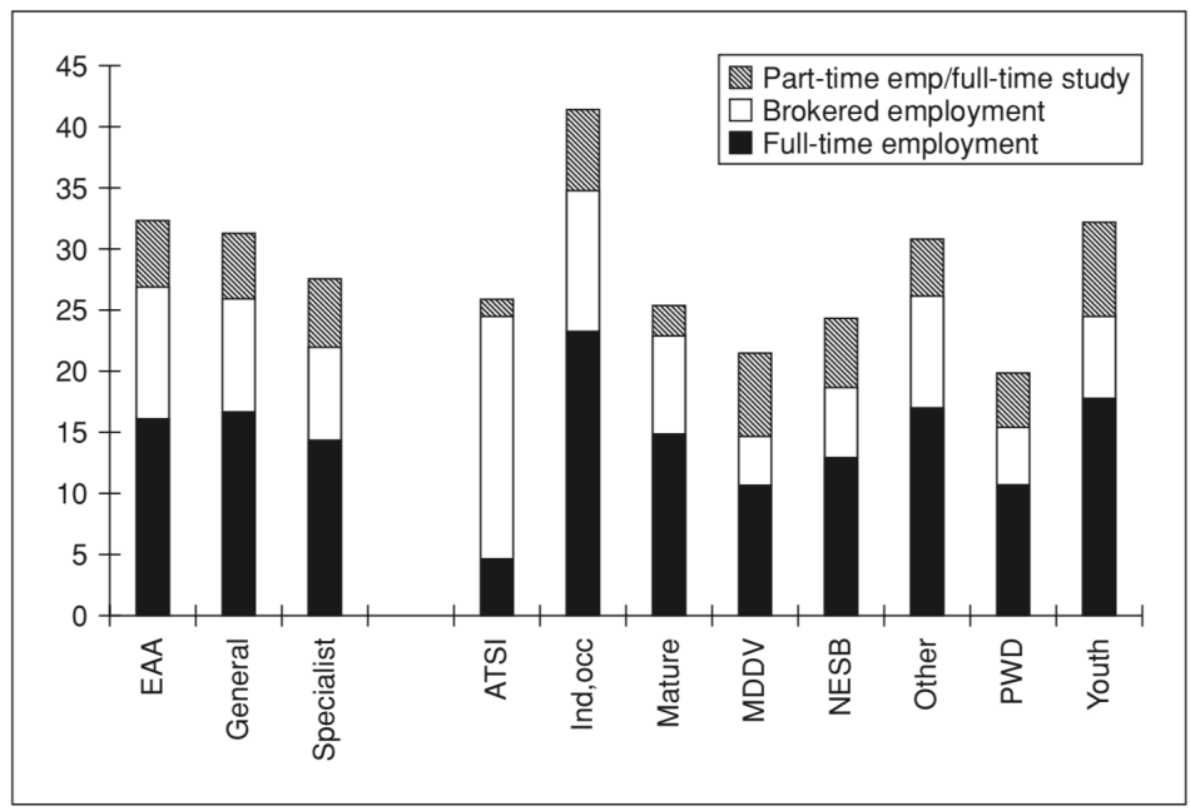

The net impact of the competitive system (see figure 6) was estimated using a cohort sample derived from the government study of long-term un- employed clients receiving benefits during this period..$^{5}$ This provided a base- line which was independent of the case management system. The cohort selected from this database was made up of unemployed people on benefits for more than twelve months who had not received case management. This shows that the success of the reforms was greatest in the first eighteen months and then declined in the six months to January 1997 when differences be- tween those getting the programme and those managing without assistance declined. This supports the conclusion that programmes in this field tend to have their best effects in the short term and should then be modified to keep them functioning effectively. However, there are reasons to doubt that these effects are confined only to this short period. First, the January to January period used in these government statistics highlights start- and end-points which have unusual attributes. The December to January period is traditionally a time of temporary Christmas work in key labour markets such as hospitality and retailing. This is a time when one might expect unsupported job seekers to fare better. Further, this is also the time when many new clients are taken into case management since this is the anniversary of their leaving school, losing their Christmas job or finding a place on the vacancy list of a service provider. ${ }^{6}$ 
Second, the trend line for both types of job seeker shows overall improvement, even though differences between the two does decline towards the end. It is plausible to argue that those not receiving case management were also subject to some of the overall programme effects. For example, the higher levels of activity required of case-managed clients, including new compliance demands, would be expected to have had some effect on the job search activities of all long-term clients. Non-case-managed clients were doubt- less aware that they might be referred to case management and this may well have encouraged higher levels of activity. Staff at the CES dealing with non-case-managed clients might also have done more to assist this group now that many of their harder clients had been transferred to other agencies.

Figure 6: Net impact of competitive case management

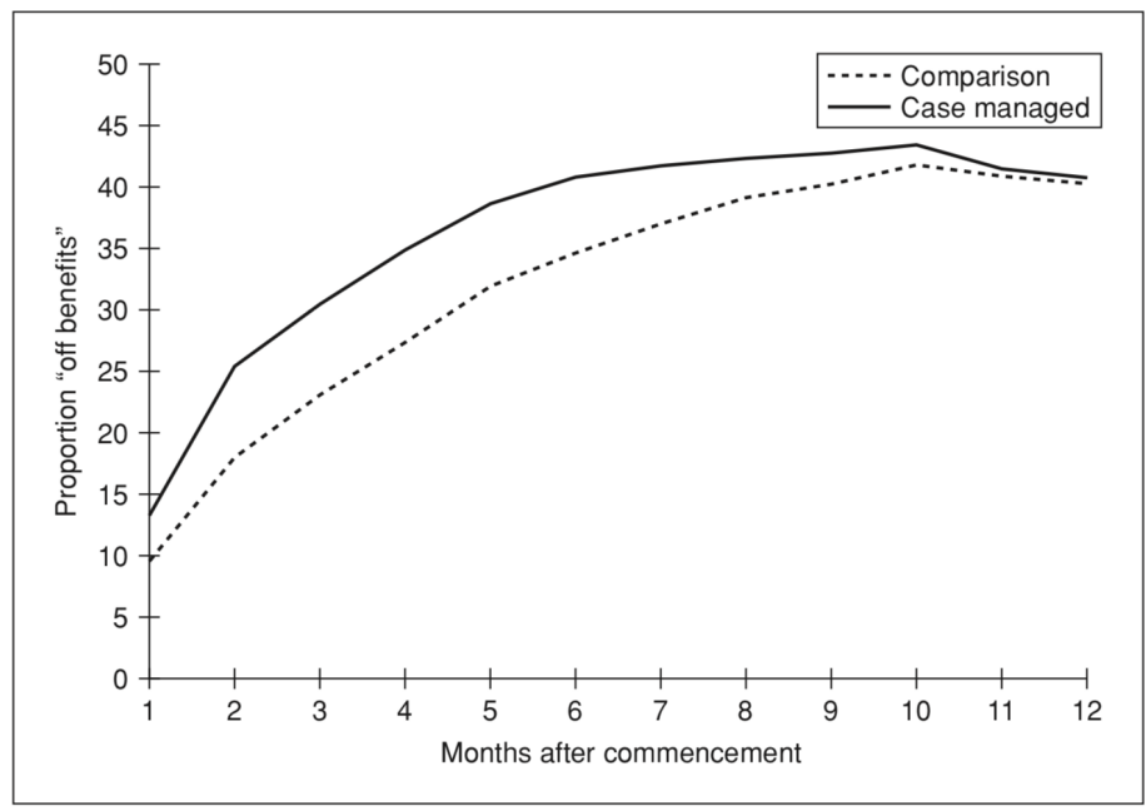

The advent of active, competitive case management might well have in- creased pressures on all job seekers to obtain any form of paid work and to cease the search for specific jobs related to previous employment history or career preference. This "change in expectations" might well be more general than just those currently receiving case management, particularly when it is recognized that both types of job seeker use the same labour exchanges and vacancy lists and presumably communicate aspects of their job search strategies to one another. Finally, the convergence of the two trend lines corresponds with the period immediately after the wind-down of subsidized programmes for those in case management. Since this appears to have a particularly harsh impact on some disadvantaged job seekers it is 
likely that this might explain much of the reduced advantage observed for case- managed clients who were selected from the most disadvantaged section of the welfare list.

In summarizing these performance data we return to the primary research question. What difference does the new welfare state (NWS) model make to the delivery of services? First, the data indicate that those non-government agencies most likely to do well, and thus to profit most, are those which operate from within their own internal network of established employment services. This appears to provide greater experience with service delivery, superior human resources, better technology in the form of educational facilities, information technology and administrative systems, and stronger forms of business planning. This also suggests a significant barrier to entry for new participants in such markets.

Second, the non-government agencies show a greater variability in performance, somewhat lower overall proportions of exits from the benefit rolls, and lower levels of sanctioning. This suggests an overall superiority in aver- age performance for the larger, nationally organized public provider. Third, the semi-competitive system (based on outcomes at a standardized price) tends to lead to better outcomes for the least disadvantaged categories of clients, other things being equal. The data available also point to declining overall performance in treatments of the most disadvantaged clients when subsidized programmes are withdrawn. This emerges most clearly in com- parisons of specialist and generalist private providers as well as in overall trends in subsidized and unsubsidized clients.

Finally, the competitive case management "market" appears to create its most significant returns in the period up to the third quarter of 1996, after which there is a convergence of outcomes for treated and untreated client cohorts. A number of factors may explain this pattern, including the end of subsidized programmes and changed expectations affecting all those involved in the employment assistance system. Nevertheless, the aggregate data point to very significant savings due to the introduction of the system over the period examined.

\section{Results 2: Explaining Good Performance}

How can these overall patterns of performance be explained at the agency level? Results from the twenty high and medium sites showed a convergence in methods of treatment according to three models of assistance. These models were derived from the coding of 
interviews and focus groups by a panel of researchers. ${ }^{7}$ None of these models was mandated by the system legislation, and nor are they explained by the literature on case management (Austin 1993; Hagen 1994). Indeed the most successful sites diverged from both the legislative model and from previous practice protocols. What distinguished better-performing sites was their ability to define a low-cost service in which clients themselves carried much of the responsibility for improving their position. Far from engaging in interactive relationshipbuilding, or networking with other agencies, employers or other service deliverers in the manner suggested by other studies (Nathan 1993; Chadwin et al. 1981; Friedlander and Burtless 1995), most agencies were small, internally focused and reluctant to invest in more expensive treatments.

The common model of assistance found in the literature and enacted in the legislation supporting the Australian reforms posits a three-part intervention (Hammond 1997; Working Nation 1994). First, case managers are thought to engage in energetic assessments of the needs of individual clients and to fashion from these a sophisticated plan for support, training and motivation. Included in this first stage is the writing of a formal agreement with the individual job seeker which contains a negotiated plan for reciprocal activity by the client and the case management agency. This authoritative plan is also deemed to be the primary instrument for obtaining compliance from clients and ensuring higher levels of job preparation and employment search.

Next, the model includes an explicit commitment to addressing the barriers that cause disadvantaged job seekers to fail in their attempts to find open employment. It is at this stage that new skills in finding work and new opportunities to develop employment skills favoured by employers are imparted by the agency, or by other service delivery organizations participating in the programme. Third, agencies are expected to develop improved methods for linking job seekers to the local labour market by providing employment leads, by individual matching of clients to vacancies, and by supporting clients and employers during the first weeks of a new job.

All the high-performing sites studied contradicted important aspects of this model, as did a number of the average sites. Most case managers reported that they spent little time contacting employers and did not devote attention to finding vacancies for their clients. Instead, they spent almost all their time in interviews and group sessions with clients, 
encouraging them to find their own jobs and occasionally helping them with personal problems. While some reported that other members of their wider organizations sometimes provided vacancy leads, in general they were unwilling to deal directly with employers because they rarely had the types of job seekers being sought. A typical response to this question was: "You hate it when they come in and say they want three welders because you know you won't have them and they will get annoyed."

Similarly, most agencies devoted their time with clients to such things as letter writing, preparation of resumes and scanning of newspapers. Officials call these activities "polishing" the clients. These low-cost interventions seldom involved the intensive one-on-one treatments described in the programme model and instead involved group activity which was sometimes supervised by clerical staff and receptionists. A number of these support staff were found to be former job seekers now being employed on subsidized work placements.

Individual work with clients was concentrated upon the initial writing of the agreement and upon regular reporting sessions at which job seekers described their recent search efforts. Only when problems occurred later in the process did case managers report a preference for more intensive interviews. The strong emphasis upon job-search skills and the avoidance of job training clearly reflected the shift in government policy which had occurred by the time this research was undertaken. However, as a result of that change, private agencies were given remaining training funds as a "cashed out" fund to use on a discretionary basis. This amounted to approximately $\$ 399$ per client. It was expected that these funds would be pooled and used for those clients who required specific assistance in the form of short training courses. Even though many of these agencies also ran their own training programmes elsewhere in their organizations and might have been expected to refer clients, only a small minority reported that they did so. Most said they did not normally use such funds on client training.

Interestingly, the best sites did not use the formal agreement process as anything more than a form of registration necessary to generate the first progress payment from government. As a result agreements tended to be extremely brief and generic. As has already been noted, private agencies showed a lower rate of sanctioning than the government provider. The pressure they put on clients to comply with programme obligations was more likely to flow 
through informal warnings and "show and tell", "name and shame" sessions at which clients reported their efforts to the case manager or to group sessions of their peers.

Some case managers also reported that when clients failed to appear for interview or did not attend designated group sessions they used the official computer system to classify the client as "no longer requiring assistance (NRA)". This resulted in a client's benefit being stopped immediately and forced him or her to immediately contact the agency in order to regain income support. This strategy was not allowed under the rules established by government and as such was a form of illegal sanctioning. Nevertheless, when used in moderation it was virtually undetectable and showed the sophistication of the compliance strategies used by the private agencies.

Since reference back to the content of the formal agreement was almost always needed to substantiate a sanction, and since case managers found it off-putting to subject job seekers to the framing of highly legalistic agreements in their first weeks, the consequent weakness of this instrument also helped explain the lower levels of official sanctioning by these agencies. Case managers also reported that they saw sanctioning as a last resort which implied a breakdown in their service and thus a loss of face for them and their agency. Unwillingness to become engaged in the legal process of sanctions and appeals was frequently cited by private case managers as a reason for not resorting to this measure.

Staff and clients were also asked in interview about the reasons why job seekers had chosen their agency. Most job seekers gave highly favourable testimony about their experiences and preferred this form of treatment to the standard processes of the government system which existed before the introduction of this programme. ${ }^{8}$ They cited more personal attention and gave examples of case managers taking a personal interest in their job-seeking activities and personal problems. Some also acknowledged being under greater pressure and occasionally complained of "herding" strategies used to drive them into the job market. Many had not exercised any choice in regard to the selection of their agency and said they had been directly referred by the Commonwealth Employment Service. Those who had made a choice most often said this was based on one or both of two factors: they did not want to be case-managed by the government office, or wished to go to the agency which was closest to where they lived. No job seeker in the twenty focus groups cited knowledge of the agency or information about its performance as a reason for their choice. This was confirmed in interviews with 
Commonwealth Employment Service staff making referrals who indicated that they were not permitted to advise clients about differences in the job placement performance of agencies in their area.

The study found three common forms of assistance among high-performing sites. These were also evident at average sites although with less uniformity and less intensity. The first approach was termed the "Standard Model" and eight sites were found using it. Four of the six average category performers were in this category. This approach treated all clients as active job seekers and moved them through a common set of search steps. Only if a client showed evidence of problems after six to eight weeks in this treatment were other individual interventions used.

The second approach was termed the "Motivational Model" and ten of the sites were found fitting this type. Since the number of sites was small it is clearly unwise to make too much of any differences between type of agency and types of strategy. Nevertheless, it is worth noting that of the ten "motivational" sites, only one was an average-performing site. This strategy made great use of individual interviews during the first weeks of case management and often was based on an explicit set of steps adopted across the organization. These included encouragement of job seekers to see themselves as more competent than before, to acknowledge personal problems, and to make more "realistic" self-assessments of their job search histories. "The relationship between the case manager and client is central to this model and is one based on . . . behaviour modelling and positive support and reinforcement" (ESRA 1997: 13).

The third model was termed the "Formal Assessment Model"" and it came closest to the common view of case management as a tool for fashioning separate treatments for each client according to need. There were only two sites found using this approach, one from each performance cluster. Here clients were given detailed tests and assignments at the start of the process to determine their skills, health problems and other barriers to employment. Both providers using this approach employed staff with backgrounds in the health professions. Following assessment, clients were then allocated either to open search activities, or were referred to specialists in the treatment of such things as drug and alcohol dependency and disability. 
Finally, the research identified important differences in the leadership styles of those managing the case management agencies. Asked to rate the organizations they visited according to the degree of participative management or more controlling behaviours, researchers placed all twenty along a continuum. Determinants of this placement included: whether or not case managers were involved individually or as a group in planning the agency's service model, business priorities, and relationships with other organizations. Also included was a rating of the extent to which the manager allowed staff to adopt individual work styles.

In the participative type staff were consulted about, and involved in, major decisions affecting the business. In the controlling type the leaders or managers intervened directly in day-to-day case management work and took a personal role in detailed allocation decisions. It was clear from these qualitative assessments by the ten researchers that most rated the motivational sites as significantly more participative than either of the other two types. This suggested a degree of consistency between practices used with clients and those used in internal management.

In summary, the evidence from this qualitative study showed important attributes of highperforming agencies: they left less to individual selection by case managers than was expected; they focused primarily on job seekers rather than employers; they did not place reliance upon detailed assessment of barriers to employment; they avoided referring clients to skills training; they did not often use their powers to sanction clients formally, and they saw their roles as strengthening search behaviour in the expectation that this would result in clients taking available jobs at the earliest opportunity.

These findings reinforce the earlier conclusions regarding disadvantaged clients. No special interventions were reserved for such clients and the pressure to increase open job searching activities by all clients may help explain why, in the absence of subsidized programmes, very disadvantaged clients did less well than others involved in the programme.

\section{Conclusions}

Forms of selective, individualized welfare assistance delivered through quasi-markets are a defining characteristic of the New Welfare State model emerging in some countries such as 
Australia, New Zealand and the USA. They propose better financial results for governments and outcomes which better meet the specific needs of clients. Moreover, the use of multiple agencies in theory offers a greater prospect of service innovation as the many independent contractors strive to earn higher returns as a result of superior placement strategies. However, these reforms also suggest new forms of exclusion and bias as agencies seek to work only with those clients who can deliver them profits.

This study has provided some baseline empirical evidence of the complex impacts which NWS reforms may have upon key social programmes. The results show some support for the claim that such systems are superior to a single service delivery model in so far as the best private agencies outperform the sole government operator. However, the greater consistency of overall performance of the government service also suggests that the public office may have advantages over its competitors. The advantages of the quasi- market appear to result from allowing more providers to experiment with different service methods and from the fact that the scale of operation of all sites is smaller and more intimate than had been the case in the previous government monopoly.

However, there are also significant problems with this New Welfare State model. Choice by clients is far less significant than the ideology of the quasi-market suggests. Furthermore, the practices of the best-performing sites indicate that such systems may regularly diverge from government policy commitments in their efforts to obtain financial results. The use of the "no longer requires assistance" (NRA) classification, the failure to allocate "cashed out" training funds, the minimal use of individual assessments, poor use of post-placement support services, and the lack of specific services for more disadvantaged clients provide great cause for concern. In short, the strength of these forms of assistance is also their primary weakness. The reliance upon short-term financial incentives leads agencies to find innovative ways to maximize a very low-cost form of intervention and to ignore other policy values (including sanctioning) which do not carry a direct monetary benefit.

\section{Acknowledgements}

The author acknowledges the invaluable assistance of Dr Owen Donald, CEO, and Karen Thorsen, Head of Research and Evaluation, Employment Services Regulatory Authority 
(ESRA), and the ESRA research team who participated in the Best Practice Study and provided access to these data. Professor Jan Carter, and the staff at Deakin Human Services Australia also supported the research throughout. Conclusions drawn from these data do not, however, necessarily reflect their views.

\section{Notes}

1. Research staff at ESRA who participated in the study team undertook these procedures using confidential performance data provided by contractors as a condition of their receiving payments under their contracts. At ESRA's request the names of these agencies have not been included in the paper.

2. These were broken down to local area level to approximate the catchments of the local office of the public agency and of private providers.

3. Unfortunately the ESRA data did not distinguish between for-profit and non- profit private agencies. For a discussion of differences between these types see my: Markets, Networks and the New Welfare State: Employment Assistance Reforms in Australia, Journal of Social Policy, 28, 2: 183-203.

4. Up to December 1996 the private agencies received 8,656 level-three clients while the public provider received only 1,132 .

5. Bureau of Statistics Australia (1997), Cohort Study of Long Term Unemployment Benefit Recipients, Canberra.

6. Performance scores decline during the first three months after an agency is granted a new set of clients, causing recently contracted agencies and those granted in- creased numbers a temporary decline in average outcomes.

7. Following the completion of fieldwork the six researchers were asked to rate the sites they visited according to the factors which made up the "common or normal system by which clients were processed". The two researchers who visited each site then reported their findings for each site to a workshop of the research group. The research group then considered the resulting matrix of factors identified in all twenty sites and identified core characteristics. These became the three types identified here. Spirited discussion of the names to give these three resulted in an agreed nomenclature. This was later modified by the ESRA Board, the commissioning agency for the Best Practice study.

8. Because the research team lacked authority to contact clients directly, those participating in focus groups came at the invitation of their case managers. This was likely to have resulted in 
stronger than average tendencies for this sample to be skewed towards more satisfied clients. Nevertheless, most groups expressed a range of opinions and seemed not to have been tutored in the responses to standard questions.

9. This model was originally described as the Professional Service Model. 


\section{References}

Austin, C. D. (1993), Developing case management: a systems perspective, Journal of Contemporary Human Services, October: 451-59.

Bartlett, W., and Harrison, L. (1993), Quasi-markets and the National Health Service reforms. In Le Grand and Bartlett: 68-92.

Barzeley, M. (1992), Breaking Through Bureaucracy: a New Vision for Managing in Government, Berkeley: University of California Press.

Brasher, C. N. (1994), Workfare in Ohio: political and socioeconomic climate and programme impact, Policy Studies Journal, 22, 3: 514-27.

Castles, F., Gerritsen, R., and Vowles, J. (eds) (1996), The Great Experiment: Labour Parties and the Transformation in Australia and New Zealand, Sydney: Allen and Unwin.

Chadwin, M., Mitchell, J. J., Hargrove, E. C., and Mead, L. (1977), The Employment Service: an Institutional Analysis, R \& D Monograph 51, Washington DC: US Department of Labor.

Chadwin, M. L., Mitchell, J. J., and Nightingale, D. S. (1981), Reforming welfare:

lessons from the WIN experience, Public Administration Review, 41, 3: 372-80.

Considine, M. (1996), Market Bureaucracy: the Changing Form of Social Administration in Australia. In A. Farrar and J. Inglis (eds), Keeping It Together: State and Civil Society in Australia, Sydney: Pluto: 76-91.

Considine, M. (1999), Markets, Networks and the New Welfare State: Employment Assistance Reforms in Australia, Journal of Social Policy, 28, 2: 183-203.

Department of Employment, Education, Training and Youth Affairs (DEETYA) (1996), Working Nation: Evaluation of the Employment, Education and Training Elements, Evaluation and Monitoring Branch Report 2/96, Canberra: DEETYA.

Employment Services Regulatory Authority (ESRA) (1997), Best Practice in Case Management, Melbourne: ESRA.

Esping-Andersen, G. (1990), Three Worlds of Welfare Capitalism, Cambridge: Polity Press. Finn, D. (1997), Working Nation: Welfare Reform and the Australian Jobs Compact for the Long Term Unemployed, Darlinghurst: ACOSS.

Foster, C., and Plowden, F. J. (1996), The State Under Stress: Can the Hollow State be Good Government?, Buckingham: Open University Press.

Friedlander, D., and Burtless, G. (1995), Five Years After: the Long-term Effects of Welfareto-work Programmes, New York: Russell Sage Foundation.

Glennerster, H. (1991), Quasi-markets for education, Economic Journal, 101, September: 1268-76.

Hagen, J. L. (1994), JOBS and case management: developments in ten states, Social Work, 39, 2: 197-205.

Hamilton, G., and Brock, T. (1994), The JOBS Evaluation: Early Lessons from Seven Sites, New York: Manpower Demonstration Research Corporation.

Hammond, B. (1997), Foundations of Case Management, Waurn Ponds: Deakin University Press. 
Handler, J. (1995), The Poverty of Welfare Reform, New Haven, CT: Yale University Press.

Handler, J., and Hasenfeld, Y. (1997), We the Poor People: Work, Poverty, and Welfare, New Haven, CT: Yale University Press.

Hardin, G. (1978), Political requirements for preserving our common heritage. In H. P. Bokaw (ed.), Wildlife and America, Washington DC: Council on Environmental Quality. Jennings, E. T., and Krane, D. (1998), Interorganizational cooperation and the implementation of welfare reform: community service employment and welfare work programmes, Policy Studies Review, Summer/Autumn, 15, 2/3, 170-201.

King, D. (1995), Actively Seeking Work? The Politics of Unemployment and Welfare in the United States and Great Britain, Chicago: University of Chicago Press.

Kooiman, J. (ed.) (1993), Modern Governance: New Government-Society Interactions, London: Sage.

Lane, R. (1991), The Market Experience, Cambridge: Cambridge University Press.

Le Grand, J., and Bartlett, W. (eds) (1993), Quasi-markets and Social Policy, London:

Macmillan.

Martinson, K., and Friedlander, D. (1994), GAIN, Basic Education in Welfare-to-work

Program, New York: Manpower Demonstration Research Corporation.

Mead, L. (1989), Beyond Entitlement: the Social Obligations of Citizenship, New York: Free Press.

Mead, L. (1989), The logic of workfare: the underclass and work policy, Annals of the American Academy of Political and Social Science, 501, January: 156-69.

Nathan, R. P. (1993), Turning Promises into Performance: the Management Challenge of Implementing Workfare, New York: Columbia University Press.

OECD (1993), PUMA Public Management, Market-Type mechanisms Series No. 6: Internal Markets, Paris: OECD.

Osborne, D., and Gaebler, T. (1993), Reinventing Government: How the Entrepreneurial Spirit Is Transforming the Public Sector, New York: Plume Books.

Ostrom, E. (1990), Governing the Commons: the Evolution of Institutions of Collective Action, Cambridge: Cambridge University Press.

Pavetti, L., Olson, K., Pindus, N., and Pernas, M. (1996), Designing Welfare-to-work Programmes for Families Facing Personal or Family Challenges: Lessons from the Field, Washington DC: Urban Institute.

Polanyi, K. (1944), The Great Transformation, Boston: Beacon Press. (Reprint 1957) Robinson, C. (1995), Employment Case Management and Public Sector Reform, Department of Prime Minister and Cabinet (PMC), 10 July, Canberra: PMC.

Rose, N. (1996), Governing "advanced" liberal democracies. In A. Barry, T. Osborne and N. Rose (eds), Foucault and Political Reason: Liberalism, Neo-liberalism and Rationalities 
of Government, London: UCL Press: 37-65.

US General Accounting Office (1995), Welfare to Work: Most AFDC Training Programmes not Emphasizing Job Placements, Washington DC: GAO.

Williamson, O. (1975), Markets, Hierarchies: Analysis and Antitrust Implications, New York:

Free Press.

Working Nation (1994), Policies and Programmes Presented by the Prime Minister, The Hon. P. J. Keating, Canberra: Australian Government Publishing Service. 